\title{
Mudança organizacional em uma empresa familiar brasileira*
}

\author{
Mario Couto Soares Pinto** \\ Cristina Lyra Couto-de-Souza***
}

SuMÁRIo: 1. Introdução; 2. Uma breve visita às teorias de mudança organizacional; 3. Alguns aspectos metodológicos; 4. O caso Famed; 5. Análise da mudança organizacional; 6. Conclusão e considerações finais.

Summary: 1. Introduction; 2 . A brief visit to the organizational change theories; 3. A few methodological aspects; 4. The case of Famed; 5. Analyzing the organizational change; 6 . Conclusion and final remarks.

Palavras-chave: mudança organizacional; gestão da mudança; empresa familiar.

KEY WORDS: organizational change; change management; family business.

Este artigo avalia a eficácia da gestão do processo de mudança organizacional de uma empresa familiar brasileira, da área de saúde, que está passando por uma fase de sucessão e busca de maior profissionalização. Para atingir o objetivo, foram realizadas pesquisa de campo e análise qualitativa, comparando os dados levantados

\footnotetext{
* Artigo recebido em abr. 2008 e aceito em mar. 2009.

** Doutor e mestre em administração de empresas pela Pontifícia Universidade Católica (PUCRio). Pós-graduado em filosofia contemporânea pela PUC-Rio. Engenheiro civil pela Universidade Federal do Rio de Janeiro (UFRJ). Professor do IAG/PUC-Rio e coordenador da Graduação em Administração da PUC-Rio. Autor de diversos artigos e livros na área de organização e recursos humanos. Trabalhou na IBM Brasil como especialista de marketing. Foi diretor acadêmico do curso de Graduação em Administração de Empresas da ESPM-Rio e professor da pós-graduação e da graduação. Endereço: Rua Marquês de São Vicente, 225 — Gávea — CEP 22453-900, Rio de Janeiro, RJ, Brasil. E-mail: mpinto@iag.puc-rio.br.

*** Doutoranda em administração de empresas na Pontifícia Universidade Católica do Rio de Janeiro (PUC-Rio). Mestre em administração de empresas pela PUC-Rio. Pós-graduada em marketing e management pelo IAG PUC-Rio. Engenheira eletrônica e de produção pela PUC-Rio. Gestora e consultora nas áreas de engenharia, marketing, planejamento estratégico e controladoria. Endereço: Rua Aperana, 52/202 — Leblon — CEP 22450-190, Rio de Janeiro, RJ, Brasil. E-mail: crislyra@gmail.com.
} 
com os conceitos identificados na literatura. Os dados foram coletados por meio de entrevistas informais, análise de documentos da empresa e observação participativa, no período de julho de 2005 a janeiro de 2006. O estudo verifica se o processo de mudança organizacional da empresa estudada foi ou não bem-sucedido e, também, $o$ avalia com base no modelo proposto por John P. Kotter para a implementação eficaz de mudanças nas organizações, comparando os oito passos propostos pelo autor com o ocorrido na empresa. A avaliação do processo de mudança levou à constatação de que ele não teve sucesso. O resultado da pesquisa sugere aplicabilidade do modelo de Kotter, já que evidencia que diversos passos apontados pelo autor não foram seguidos e tal fato ocasionou problemas no processo de mudança da organização.

\section{Organizational change in a Brazilian family business}

This article assesses the effectiveness of management of the organizational change process and in a Brazilian family business in the healthcare sector. The business is undergoing a succession process and wants to improve its professional profile. The study consisted of a field research and a quality analysis that compared the data obtained and the concepts identified in a selected literature. Data was collected through informal interviews, analysis of the company's documents and through participant observation, from July 2005 to January 2006. This article shows if the organizational change process has succeeded or not, also considering the model proposed by John P. Kotter for the efficient implementation of changes in organizations, comparing the eight-stage change process proposed by that author to what actually happened in the company. The analysis of the change process led to the conclusion that it was unsuccessful. It suggests that Kotter's model is applicable to the situation studied since it shows that several stages mentioned by the author were not followed and this fact has caused problems in the organizational change process.

\section{Introdução}

Não são poucos os autores em administração que registram um significativo deslocamento das prioridades dos gestores no decorrer do século XX e no início do atual. Se antes havia necessidade de otimização dos processos produtivos, a maior parte emergia das empresas. Ao contrário do que percebemos hoje em dia, a empresa estava totalmente voltada à redução de desperdícios e aumento da produção, havendo pouca preocupação com transformações radicais no produto ou no processo. A crença principal era de que um bom produto teria suas vendas asseguradas, caso cumprisse um padrão razoável de qualidade. No cenário atual, com as sucessivas rupturas tecnológicas, com o aumento e diversificação da força de trabalho, com a globalização, com o crescimento da competição etc., a empresa se depara com uma realidade de maior dinamismo, que exige um importante e contínuo incremento de competitividade para 
dar conta de mercados mais agressivos com consumidores mais exigentes. Com isso, as mudanças nas organizações precisam ser mais frequentes, mais rápidas e, grande parte das vezes, mais profundas, conforme assevera Wood Jr. (2000), ao afirmar que a mudança não é, hoje, uma opção. Aponta o autor que as empresas têm gradativamente abandonado uma postura reativa para assumir uma postura proativa frente às mudanças. Para Souza Silva (2003), a questão que desafia os interessados no tema é como gerenciar a mudança organizacional se, historicamente, a ciência da administração se preocupou em formar administradores da eficiência e não gerentes da mudança. Já Neiva (2003) entende que aspectos vitais como o processo de implementação, a eficácia do desenho, o papel e a eficiência dos responsáveis e o impacto desses programas ainda estão longe de apresentar respostas mais conclusivas.

Considerando tal realidade, estudos que façam avaliações de intervenções para a mudança organizacional suscitam interesse na medida em que permitem tanto a orientação empírica dos responsáveis pelo processo de transformação, quanto a avaliação da pertinência e da atualidade de determinado constructo teórico.

Diante dos desafios mencionados, a intenção deste artigo é fornecer auxílio aos gestores de organizações imersas em uma realidade repleta de fúria e som, e que se transforma a cada olhar. Sua relevância aumenta quando se observa que a mudança em tela abraça uma empresa nacional, familiar, de médio porte, que enfrenta um processo de sucessão em sua estrutura administrativa e busca maior profissionalização. Representa um padrão comum no cenário das empresas brasileiras. Ademais, a organização atua em uma área extremamente vital e carente de nossa sociedade, o setor hospitalar, o que adiciona uma tonalidade social à presente investigação.

Partindo da premissa de que o fenômeno de mudança organizacional pode ser gerenciado, a pesquisa verificou se o processo ocorrido na empresa estudada foi ou não bem-sucedido ao avaliá-lo conforme o modelo proposto por John P. Kotter para a implementação eficaz de mudanças nas organizações. Identificadas as falhas, este artigo sugeriu melhorias ou caminhos alternativos para a gestão da mudança. Para isso, foi realizada uma comparação de cada passo do modelo proposto por Kotter $(1996 ; 1998)$ com o ocorrido no processo de mudança da empresa estudada.

Cabe ressaltar que, devido à diversidade de significados atribuídos ao conceito de mudança pelos diferentes autores da administração, estabeleceuse como recorte a taxionomia de Ford e Ford (1995) e Nadler e colaboradores (1994), que sugerem uma definição de mudança organizacional como intencional e descontínua, respectivamente. Ou seja, mudança é um processo 
iniciado de maneira deliberada e consciente, envolvendo o redesenho de características estruturais da empresa analisada.

Este artigo foi estruturado em cinco seções, além desta introdução. Na segunda, são tratados alguns conceitos de mudança no decorrer de uma breve revisão bibliográfica. Na terceira seção é apresentada, de forma sucinta, a metodologia que foi utilizada na pesquisa. A quarta apresenta o levantamento de dados realizado na empresa. Na quinta seção está a análise da mudança com base no resultado da pesquisa de campo e no referencial teórico apresentado, especialmente no modelo proposto por John P. Kotter. Finalmente, na última seção são apresentadas as conclusões, as considerações finais e as sugestões para futuras pesquisas.

\section{Uma breve visita às teorias de mudança organizacional}

Aqui faremos uma breve revisão da literatura sobre como as questões relativas à mudança organizacional e à gestão da mudança têm sido tratadas nas teorias da administração, envolvendo tanto discussões acerca do conceito de mudança quanto apresentação de alguns modelos. Tais discussões se encerram com a escolha do modelo adotado para o estudo de caso deste artigo.

\section{Mudança organizacional: um esforço de conceituação}

A mudança organizacional não é uma questão nova dentro da literatura sobre organizações. É possível visualizar uma grande convergência entre alguns dos textos mais antigos e outros mais recentes que tratam do assunto. A novidade é o ritmo, além da força, com que as alterações do ambiente vêm sendo impostas às organizações. Para Huber e Glick (1995), esse ritmo veloz da mudança é provocado por duas forças no ambiente organizacional: a crescente efetividade da tecnologia de informação e da tecnologia de transporte. Silva (1999) afirma que estamos vivendo uma mudança de época, e não uma época de mudanças, devido à profundidade das alterações que vêm ocorrendo desde o final do século passado na estrutura social. Rondeau (1999) sugere que as organizações mudam porque a maneira de pensar a gestão também sofre modificações com o tempo. Isso acontece tanto pelo surgimento de novos modelos de gestão e novas ferramentas, quanto pela própria evolução das correntes de pensamento em administração e gestão de empresas.

Para Souza Silva (2003) os gerentes da época do industrialismo foram racionais, e os atuais são conceituais, contextuais, e com grande sensibilidade humana, social, cultural, ecológica e comunicativa. Sua reflexão rejeita a con- 
cepção da organização percebida como algo objetivo e independente da nossa percepção. Nessa visão, a mudança é tratada de forma equivocada, como um instrumento para mudar coisas, mas não para mudar pessoas. As pessoas costumam ser pressionadas para se adaptarem às mudanças realizadas na dimensão dura das organizações, porém suas concepções de mundo, da natureza, da organização, do futuro e dos fins não mudam. Ainda segundo Souza Silva (2003), a literatura internacional registra que as teorias derivadas das contribuições clássicas de Adam Smith, Karl Marx, Émile Durkheim, Max Weber, Frederick Winslow Taylor, Henri Fayol e Chester Bernard estão em declínio, e novas contribuições teóricas para a gestão da mudança organizacional estão surgindo.

A partir da riqueza de opções teóricas a serem seguidas, para uma discussão sobre mudança impõe-se um significativo esforço no sentido de delimitação do conceito. Com base em uma revisão detalhada da literatura, Lima e Bressan (2003) reúnem diversas definições para o conceito de mudança organizacional, apresentadas no quadro 1.

As autoras complementam o quadro com a definição de mudança proposta por Porras e Robertson (1992) que se baseia na categoria da mudança: planejada ou não. Esses autores ressaltam que a mudança planejada é aquela resultante de intervenções gerenciais, objetivando melhorias dos desempenhos organizacional e individual. Para os autores, a mudança no comportamento dos membros da organização é a essência da mudança organizacional e, além disso, qualquer mudança de sucesso só consegue persistir no tempo se, em resposta às mudanças nas características organizacionais, os indivíduos alteram seu comportamento de maneira apropriada.

Com base nessas considerações, Lima e Bressan (2003:25) propõem o conceito para mudança organizacional que foi considerado neste artigo:

Mudança organizacional é qualquer alteração, planejada ou não, nos componentes organizacionais - pessoas, trabalho, estrutura formal, cultura - ou nas relações entre a organização e seu ambiente, que possam ter consequências relevantes, de natureza positiva ou negativa, para eficiência, eficácia e/ou sustentabilidade organizacional.

Os diferentes focos de abordagem da mudança organizacional dão origem a uma variedade considerável de classificações. Apesar de alguns autores afirmarem, com veemência, que a mudança não pode ser gerenciada, boa parte dos textos encontrados na literatura diz que isso é possível. A partir daí, percebe-se a importância de se identificar os diferentes tipos de mudança, permitindo ao gerente aumentar seu potencial de intervenção, agindo de acordo com a situação com que deve lidar. 


\section{Quadro 1 \\ Algumas definições de mudança organizacional}

\begin{tabular}{|c|c|}
\hline Definição encontrada & Referência \\
\hline $\begin{array}{l}\text { Conjunto de teorias, valores, estratégias e técnicas cientificamente embasadas, } \\
\text { visando mudança planejada do ambiente de trabalho com o objetivo de elevar o } \\
\text { desenvolvimento individual e o desempenho organizacional. }\end{array}$ & $\begin{array}{l}\text { Porras e } \\
\text { Robertson } \\
\text { (1992) }\end{array}$ \\
\hline $\begin{array}{l}\text { Acontecimento temporal estritamente relacionado a uma lógica, ou ponto de vista } \\
\text { individual, que possibilita às pessoas pensarem e falarem sobre a mudança que } \\
\text { percebem. }\end{array}$ & $\begin{array}{l}\text { Ford e Ford } \\
\text { (1995) }\end{array}$ \\
\hline $\begin{array}{l}\text { Resposta da organização às transformações que vigoram no ambiente, com o intuito } \\
\text { de manter a congruência entre os componentes organizacionais (trabalho, pessoas, } \\
\text { arranjos/estrutura e cultura). }\end{array}$ & $\begin{array}{l}\text { Nadler et al. } \\
\text { (1994) }\end{array}$ \\
\hline $\begin{array}{l}\text { Qualquer transformação de natureza estrutural, estratégica, cultural, tecnológica, } \\
\text { humana ou de outro componente, capaz de gerar impacto em partes ou no } \\
\text { conjunto da organização. }\end{array}$ & Wood Jr. (2000) \\
\hline $\begin{array}{l}\text { Qualquer modificação, planejada ou não, nos componentes organizacionais formais } \\
\text { e informais mais relevantes (pessoas, estruturas, produtos, processos e cultura); } \\
\text { modificação que seja significativa, atinja a maioria dos membros da organização } \\
\text { e tenha por objetivo a melhoria do desempenho organizacional em resposta às } \\
\text { demandas internas e externas. }\end{array}$ & Bressan (2001) \\
\hline
\end{tabular}

Fonte: Lima e Bressan (2003).

Em sua revisão de literatura, Lima e Bressan (2003) apresentam várias classificações, mas destacam que a tipologia de mudança organizacional mais amplamente divulgada refere-se à mudança transformacional versus incremental. O quadro 2 apresenta algumas das tipologias identificadas pelas autoras, acrescidas da classificação de Ford e Ford (1995) sobre a intencionalidade das mudanças e dos dois diferentes critérios de classificação de Mintzberg, Ahlstrand e Lampel (1998). O primeiro é baseado na amplitude da mudança e o segundo trata da forma como é conduzido o processo.

Com base nos diferentes critérios apreendidos da literatura sobre mudança, Silva (2001) propõe uma síntese de classificação apresentada no quadro 3. Segundo o autor, é importante ressaltar que, por conta das ambiguidades existentes na forma como os termos são utilizados nos diferentes critérios presentes na literatura, foram realizadas algumas escolhas quanto à sua utilização, podendo essa seleção não ser coincidente com as escolhas de outros autores. Deve-se observar também que as diferentes dimensões apresentadas podem influenciar-se mutuamente, e que os tipos de mudança identificados em cada uma delas devem ser entendidos como posições de um mesmo contínuo e não como elementos discretos. 


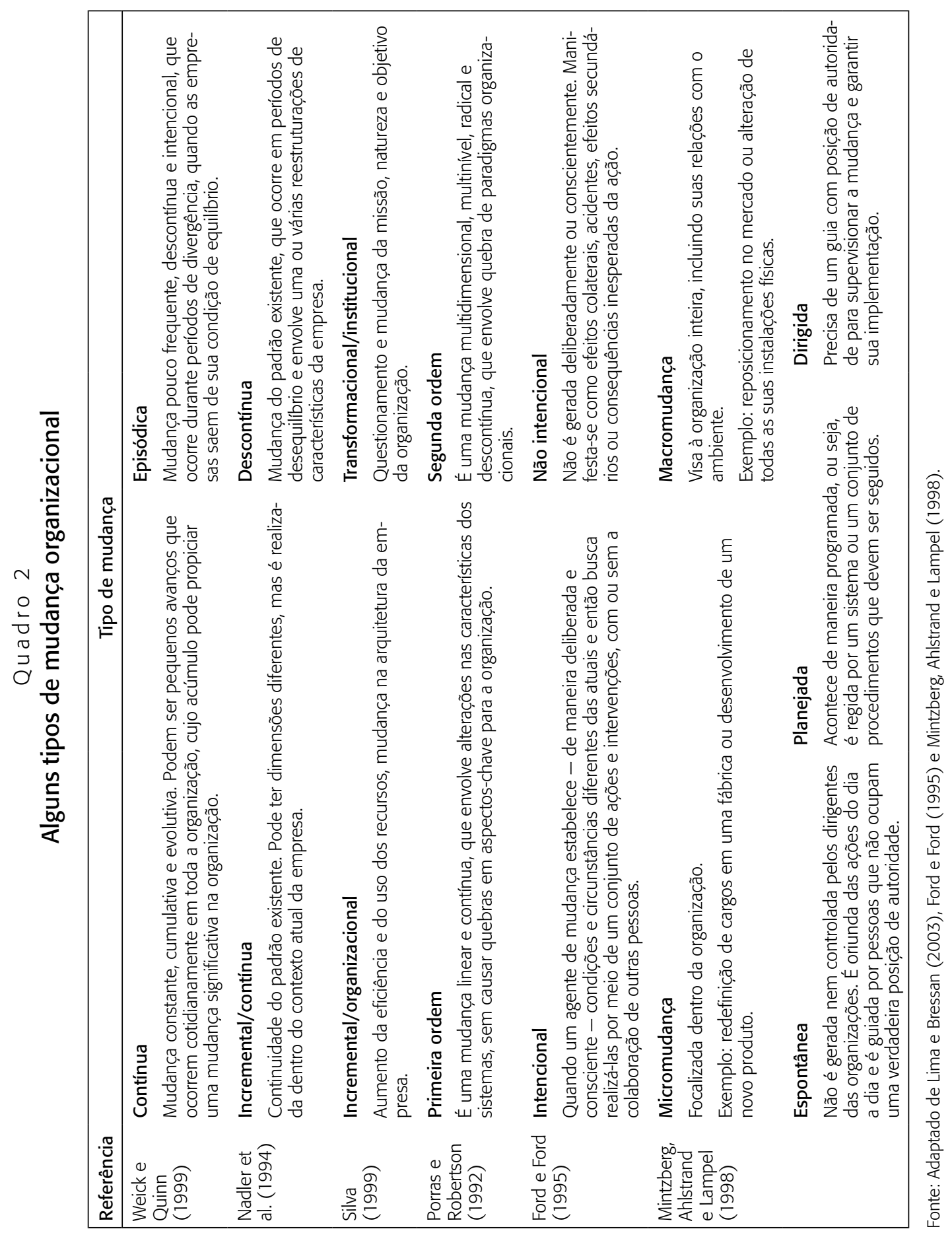


Quadro 3

\section{Síntese dos critérios de classificação observados na literatura sobre a mudança}

\begin{tabular}{|c|c|}
\hline Tipo de critério & Classificações da mudança organizacional \\
\hline \multirow[t]{2}{*}{ Quanto à intencionalidade } & $\begin{array}{l}\text { Intencional (também chamada de deliberada) - aquela cujo processo é } \\
\text { originado, conscientemente, por uma decisão da organização. }\end{array}$ \\
\hline & $\begin{array}{l}\text { Não intencional (também chamada de emergente) - aquela cujo } \\
\text { processo tem origem em circunstâncias não previstas e que acontece sem } \\
\text { que a organização tenha assumido uma opção consciente para realizá-la. }\end{array}$ \\
\hline \multirow[t]{3}{*}{$\begin{array}{l}\text { Quanto ao controle sobre } \\
\text { o processo }\end{array}$} & $\begin{array}{l}\text { Programada (também chamada de planejada - é importante ressaltar } \\
\text { aqui que existe certa ambiguidade planejada no emprego do termo, } \\
\text { que algumas vezes é utilizado como sinônimo de mudança intencional) } \\
\text { - aquela cujo processo segue uma sequência de eventos projetados pela } \\
\text { organização. }\end{array}$ \\
\hline & $\begin{array}{l}\text { Dirigida - aquela em que, embora não haja uma sequência rígida de } \\
\text { eventos programados, o controle do processo é assumido pela direção da } \\
\text { organização. }\end{array}$ \\
\hline & $\begin{array}{l}\text { Espontânea - aquela que acontece sem que a direção da organização } \\
\text { tenha o controle sobre o processo. }\end{array}$ \\
\hline \multirow{2}{*}{$\begin{array}{l}\text { Quanto à amplitude das } \\
\text { dimensões organizacionais } \\
\text { afetadas }\end{array}$} & $\begin{array}{l}\text { Macro - aquela que envolve uma grande variedade de dimensões inter- } \\
\text { nas e externas da organização. }\end{array}$ \\
\hline & $\begin{array}{l}\text { Micro - aquela que acontece de modo local, interno à organização, envol- } \\
\text { vendo um conjunto restrito de dimensões. }\end{array}$ \\
\hline \multirow[t]{2}{*}{$\begin{array}{l}\text { Quanto à frequência de } \\
\text { ocorrência }\end{array}$} & $\begin{array}{l}\text { Evolutiva (também chamada de incremental) - aquela que tende a ser } \\
\text { composta por pequenas alterações que acontecem de modo sequencial, } \\
\text { frequente, mas que, em longo prazo, podem produzir grandes alterações } \\
\text { em diferentes dimensões da organização. }\end{array}$ \\
\hline & $\begin{array}{l}\text { Episódica (também chamada de intermitente) - aquela cujo processo é } \\
\text { marcado por um início, meio e fim, geralmente em um curto espaço de } \\
\text { tempo. }\end{array}$ \\
\hline \multirow[t]{2}{*}{$\begin{array}{l}\text { Quanto à profundidade } \\
\text { das alterações provocadas } \\
\text { na organização }\end{array}$} & $\begin{array}{l}\text { Normal (também chamada de marginal ou contínua) - aquela que tende } \\
\text { a provocar pequenas alterações no conjunto global de dimensões da } \\
\text { organização, com relação ao estado inicial. }\end{array}$ \\
\hline & $\begin{array}{l}\text { Radical (também chamada de severa ou descontínua) - aquela que } \\
\text { tende a provocar grandes alterações no conjunto global de dimensões da } \\
\text { organização. }\end{array}$ \\
\hline \multirow[t]{2}{*}{$\begin{array}{l}\text { Quanto ao principal tipo } \\
\text { de conteúdo afetado }\end{array}$} & $\begin{array}{l}\text { De natureza predominantemente técnica/econômica - a que tende a } \\
\text { afetar mais as dimensões estruturais, processuais, tecnológicas e econômi- } \\
\text { cas do que as relações humanas na organização. }\end{array}$ \\
\hline & $\begin{array}{l}\text { De natureza predominantemente humana/social - aquela que tende } \\
\text { a afetar mais as relações humanas da organização do que as dimensões } \\
\text { estruturais, processuais, tecnológicas e econômicas. }\end{array}$ \\
\hline
\end{tabular}

Fonte: Adaptado de Silva (2001). 
Silva (2001) acredita que, apesar de não representar toda a gama de classificações que pode ser encontrada na literatura sobre a mudança organizacional, essa variedade de critérios apresentados no quadro 3 é suficiente para demonstrar a diversidade de enfoques que têm sido adotados para a abordagem do tema nas teorias da administração.

\section{O que mudar e como mudar: o modelo de Kotter}

O modelo clássico do processo de mudança organizacional é baseado na proposta de Kurt Lewin para a mudança social. Lewin (1951) notou que muitas vezes a mudança persistia apenas durante um curto intervalo de tempo até que as pessoas e as condições revertessem ao seu estado anterior. De acordo com o autor, para que as mudanças sejam bem-sucedidas, as organizações devem seguir três etapas: o descongelamento do status quo, o movimento para uma nova condição e o recongelamento da mudança para torná-la permanente. Apesar de ter sido concebido em 1951, este modelo ainda é extremamente popular, podendo ser encontrado em diversas versões, enriquecido pela visão de diferentes especialistas do desenvolvimento organizacional. Outros modelos tratam da forma como a mudança ocorre, e se preocupam com sua implementação e em como gerenciá-la. Em sua revisão da literatura sobre a metodologia para a gestão da mudança, Francisco (2003) destaca os modelos de Kerr e Ulrich (citados por Becker, Huselid e Ulrich, 2001) e Hammer (2002), entre outros, e muitos deles indicam passos para a implementação eficaz de mudanças.

Afinada com essa orientação está a proposta de Kotter (1998), citada com frequência por conta de sua atualidade e abrangência, além de sua preocupação em compreender as razões dos fracassos de boa parte dos esforços em transformações empresariais. Esse autor acredita que, apesar das particularidades de cada caso, a maioria dos processos de mudança envolve oito erros críticos, apresentados no quadro 4.

\section{Quadro 4}

\section{Oito erros fatais em um processo de mudança}

\begin{tabular}{|ll|}
\hline $\begin{array}{l}\text { Permitir complacência } \\
\text { excessiva. }\end{array}$ & $\begin{array}{l}\text { O maior erro cometido pelos gestores da mudança é não estabelecer um } \\
\text { sentido de urgência entre os membros da organização. A dificuldade em } \\
\text { fazer com que os indivíduos abandonem suas zonas de conforto costuma } \\
\text { ser subestimada. }\end{array}$ \\
$\begin{array}{l}\text { Falhar na criação de } \\
\text { uma coalizão administra- } \\
\text { tiva forte. }\end{array}$ & $\begin{array}{l}\text { Os altos executivos devem se comprometer com a mudança e montar um } \\
\text { grup equipe. Nos casos em que essa coalizão não é suficientemente forte, os } \\
\text { progressos tendem a ser apenas aparentes e momentâneos. }\end{array}$
\end{tabular}

Continua 


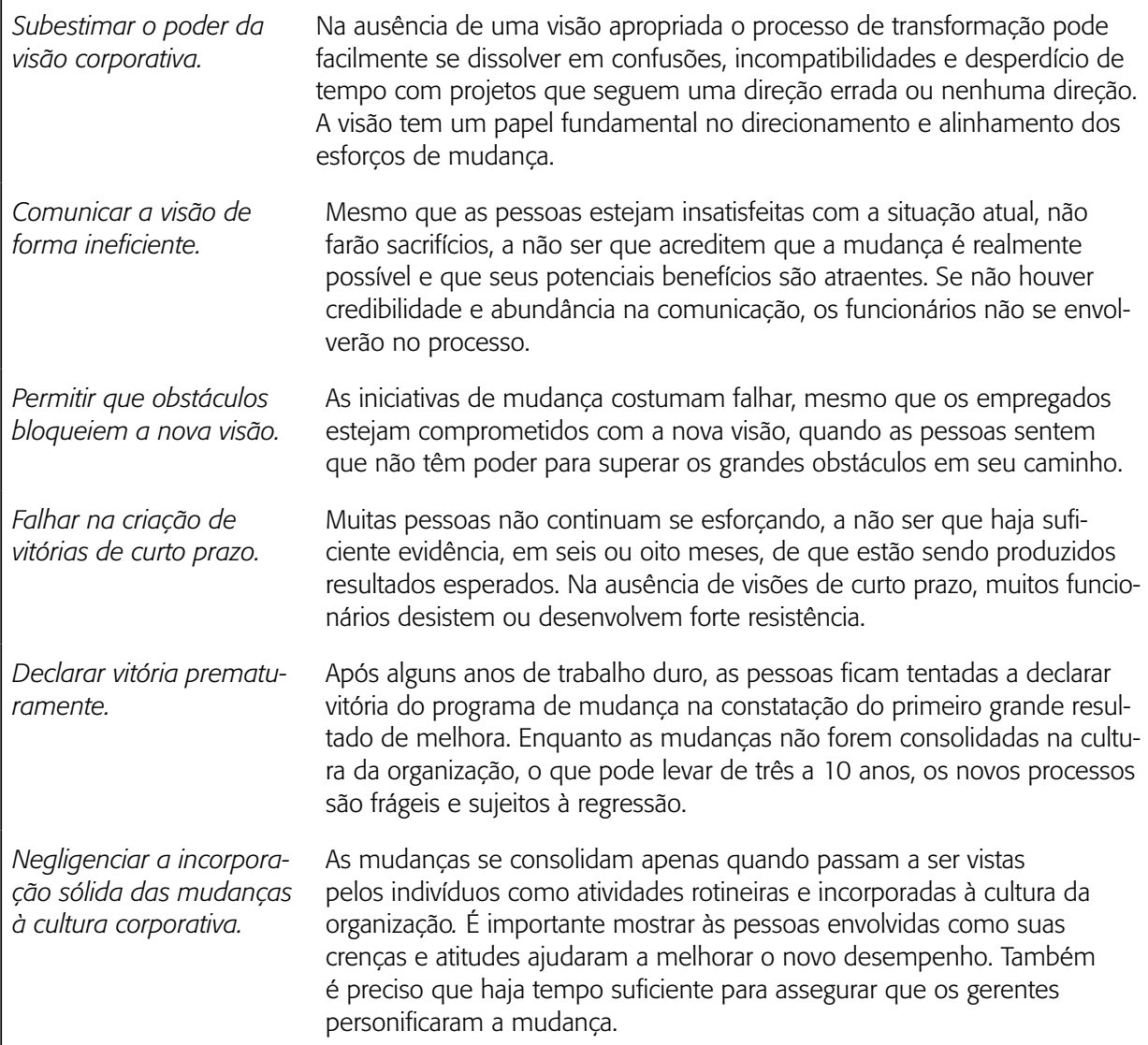

Na ausência de uma visão apropriada o processo de transformação pode facilmente se dissolver em confusões, incompatibilidades e desperdício de tempo com projetos que seguem uma direção errada ou nenhuma direção. A visão tem um papel fundamental no direcionamento e alinhamento dos esforços de mudança.

Mesmo que as pessoas estejam insatisfeitas com a situação atual, não farão sacrifícios, a não ser que acreditem que a mudança é realmente possível e que seus potenciais benefícios são atraentes. Se não houver credibilidade e abundância na comunicação, os funcionários não se envolverão no processo.

As iniciativas de mudança costumam falhar, mesmo que os empregados estejam comprometidos com a nova visão, quando as pessoas sentem que não têm poder para superar os grandes obstáculos em seu caminho.

Muitas pessoas não continuam se esforçando, a não ser que haja suficiente evidência, em seis ou oito meses, de que estão sendo produzidos resultados esperados. Na ausência de visões de curto prazo, muitos funcionários desistem ou desenvolvem forte resistência.

Após alguns anos de trabalho duro, as pessoas ficam tentadas a declarar vitória do programa de mudança na constatação do primeiro grande resultado de melhora. Enquanto as mudanças não forem consolidadas na cultura da organização, o que pode levar de três a 10 anos, os novos processos são frágeis e sujeitos à regressão.

As mudanças se consolidam apenas quando passam a ser vistas pelos indivíduos como atividades rotineiras e incorporadas à cultura da organização. É importante mostrar às pessoas envolvidas como suas crenças e atitudes ajudaram a melhorar o novo desempenho. Também é preciso que haja tempo suficiente para assegurar que os gerentes personificaram a mudança.

Fonte: Adaptado de Kotter (1996).

O modelo de Kotter se desenvolve, então, a partir da análise desses erros - identificados pelo autor como cruciais no insucesso da implementação de mudanças organizacionais - e apresenta uma sequência de oito etapas, resumidas no quadro 5, para preveni-los ou eliminá-los. Kotter (1998) indica que esses são os oito passos necessários para a implementação efetiva de um processo de mudança. Para o autor, as mudanças de sucesso de qualquer magnitude passam por esses oito estágios, usualmente na sequência apresentada no quadro 5. Embora normalmente as organizações operem em múltiplas fases simultaneamente, o autor acredita que pular, mesmo que apenas um dos passos, ou se afastar da ordem proposta sem uma base sólida pode criar dificuldades para aquele encarregado de conduzir o processo de mudança. 
Quadro 5

\section{O processo de oito passos para implementação de mudanças de sucesso}

\begin{tabular}{|c|c|}
\hline $\begin{array}{l}\text { Estabelecer um senso de } \\
\text { urgência. }\end{array}$ & $\begin{array}{l}\text { Examinar o mercado e as realidades competitivas. Identificar e analisar } \\
\text { crises, ameaças e oportunidades. }\end{array}$ \\
\hline $\begin{array}{l}\text { Criar uma coalizão para a } \\
\text { liderança. }\end{array}$ & $\begin{array}{l}\text { Reunir um grupo com poder suficiente para liderar a mudança. Garantir } \\
\text { que esse grupo trabalhe como uma equipe. }\end{array}$ \\
\hline $\begin{array}{l}\text { Desenvolver visão e } \\
\text { estratégia. }\end{array}$ & $\begin{array}{l}\text { Criar uma visão que ajude a direcionar os esforços de mudança. } \\
\text { Desenvolver estratégias para atingir esses objetivos. }\end{array}$ \\
\hline $\begin{array}{l}\text { Comunicar a visão da } \\
\text { mudança. }\end{array}$ & $\begin{array}{l}\text { Utilizar todos os veículos possíveis para comunicar constantemente } \\
\text { a nova visão e suas estratégias. Fazer com que o grupo responsável } \\
\text { pela liderança do processo modele o comportamento esperado dos } \\
\text { funcionários. }\end{array}$ \\
\hline $\begin{array}{l}\text { Dar empowerment aos } \\
\text { funcionários para realização } \\
\text { de ações abrangentes. }\end{array}$ & $\begin{array}{l}\text { Eliminar os obstáculos. Modificar os sistemas de estruturas que obstruem } \\
\text { a visão de mudança. Encorajar os funcionários a assumirem riscos e } \\
\text { estimular ideias, atividades e ações não tradicionais. }\end{array}$ \\
\hline $\begin{array}{l}\text { Gerar vitórias de curto } \\
\text { prazo. }\end{array}$ & $\begin{array}{l}\text { Planejar visões de ganho ou melhorias de performance. Criar esses } \\
\text { ganhos. Reconhecer visivelmente e recompensar as pessoas que } \\
\text { tornaram esses ganhos possíveis. }\end{array}$ \\
\hline $\begin{array}{l}\text { Consolidar os ganhos e } \\
\text { produzir mais mudanças. }\end{array}$ & $\begin{array}{l}\text { Utilizar o aumento de credibilidade para modificar sistemas, estruturas e } \\
\text { políticas que não estejam harmonizados entre si e não sejam adequados } \\
\text { à visão da mudança. Contratar, promover e desenvolver pessoas que } \\
\text { possam implementar a visão da mudança. Revigorar o processo com } \\
\text { novos projetos, temas e agentes de mudança. }\end{array}$ \\
\hline $\begin{array}{l}\text { Incorporar as mudanças à } \\
\text { cultura da organização. }\end{array}$ & $\begin{array}{l}\text { Gerar melhoria de performance por meio de comportamento orientado } \\
\text { para o consumidor e para a produção, aumentar e melhorar a liderança } \\
\text { e criar um gerenciamento mais efetivo. Articular conexões entre os novos } \\
\text { comportamentos e o sucesso da organização. Desenvolver maneiras de } \\
\text { assegurar o desenvolvimento de lideranças e sucessão. }\end{array}$ \\
\hline
\end{tabular}

Fonte: Adaptado de Kotter (1996).

Tomando por base tal orientação teórica, foi possível desenvolver um trabalho de investigação, estruturado a partir da metodologia a seguir.

\section{Alguns aspectos metodológicos}

O processo de coleta de dados passou por fases distintas, como: pesquisa bibliográfica, investigação documental e pesquisa de campo, além de observação participante e de entrevistas. O levantamento de dados para a descrição e avaliação do processo de mudança deste artigo foi realizado por uma pesquisadora inserida na empresa, fazendo parte de seu quadro de funcionários durante os sete meses do período de coleta, atuando em observação participativa. Foi possível a realização de entrevistas informais com funcionários, análise 
documental e participação em diversas reuniões gerenciais que possibilitaram a compreensão de peculiaridades e complexidades dos vários contextos organizacionais.

Foram entrevistados seis gestores (área médica, operacional, financeira, apoio ao cliente, informática e saúde preventiva), o supervisor de uma das unidades, o diretor e um de seus assessores. As entrevistas foram realizadas em ambientes informais no âmbito da convivência diária na organização e abordavam aspectos relativos ao histórico da organização, o processo de mudança, a rotina de trabalho, a relação com os colegas e com o diretor, e a visão de futuro. Os dados mais relevantes eram registrados por escrito durante a entrevista e, ao término, era feito um resumo de toda a conversa.

Graças à concordância da direção da empresa com a realização da pesquisa, foi facilitado o acesso a diversos documentos significativos para a avaliação do processo de mudança organizacional no período selecionado. Foram avaliados documentos específicos do processo de mudança e outros, referentes à rotina diária da organização.

A participação em diversas reuniões ligadas direta ou indiretamente ao tema também foi extremamente relevante na obtenção de informações pertinentes, principalmente no que se refere às opiniões dos gestores sobre a organização. Os dados foram coletados entre julho de 2005 e janeiro de 2006, e o trabalho no campo possibilitou o cruzamento com os resultados obtidos nas análises documental e bibliográfica.

Os dados coletados foram tratados qualitativamente e, para isso, foi utilizada a técnica da análise de conteúdo, proposta por Bardin (1977), na qual a organização da análise é feita em torno de três polos cronológicos: a pré-análise, a descrição analítica e a interpretação referencial. O estudo concentrouse no período compreendido entre agosto de 2004, momento da criação da primeira unidade Famed Rede, e janeiro de 2006, encerramento da coleta de dados da pesquisa. O período foi escolhido por caracterizar de forma reveladora as mudanças sofridas pela empresa e por ser acessível ao pesquisador.

\section{0 caso Famed}

A seguir, é apresentado um breve histórico e uma contextualização da organização pesquisada. A partir desse mapeamento, o processo de mudança organizacional é descrito com base na pesquisa de campo. 


\section{Apresentação da empresa}

A Famed é uma empresa de porte médio, classificada pela Abramge (Associação Brasileira de Medicina de Grupo), como uma das 30 maiores empresas de medicina de grupo no Brasil. Sua história volta aos anos 1960, quando um grupo de médicos, de um centro de excelência de medicina na época, criou a empresa com a proposta de cuidar da saúde das pessoas, tendo como objetivo o equilíbrio e a qualidade de vida, dentro e fora das empresas. Ao longo dos anos que se seguiram, a Famed foi administrada quase exclusivamente por médicos, até que, no ano 2000, iniciou-se um projeto de gestão profissional. Houve uma grande mudança no organograma, e o principal executivo passou a ser o filho do fundador da empresa - um economista. Gradativamente, ele foi assumindo o controle da organização e provocando diversas transformações. Entre outras mudanças, vários diretores deixaram a empresa e cargos importantes passaram a ser ocupados por profissionais não médicos.

A Famed, originalmente uma única empresa, sempre exerceu atividades de uma operadora de planos de saúde e de uma rede própria. No processo de profissionalização, foi identificada a necessidade de separação dessas duas atividades, dando origem à Famed Rede e à Famed Planos. A Famed Rede é composta por um grupo de hospitais e centros médicos que oferecem um grande complexo de serviços de saúde, incluindo consultas médicas, exames, internações e procedimentos hospitalares. A Famed Planos é uma operadora de planos de saúde que administra a saúde de seus assegurados, que também se utilizam das unidades e serviços próprios, a Famed Rede. Devido ao fato de as duas atividades funcionarem de forma simultânea e complementar, algumas vezes fica difícil visualizar a separação das duas organizações.

No começo de 2003 foi implementado um novo desenho para organização dos serviços médicos, com a inclusão da figura dos chefes de especialidades, para fortalecer e separar as funções típicas de uma rede de hospitais e centros médicos das funções típicas de uma operadora de planos de saúde. Finalmente, em agosto de 2004, foi anunciada a mudança que é o objetivo deste artigo: a criação da Famed Rede.

\section{O ponto de partida do processo de mudança: a paralisação}

Na carta de anúncio da inauguração oficial da primeira unidade Famed Rede, em 2004, foram apresentados: o modelo de gestão de saúde da empresa, a nova estrutura de organização e os motivos para a separação. De acordo com o 
documento, embora as duas operações tivessem o mesmo objetivo e a mesma missão de proporcionar saúde e qualidade de vida para as pessoas, ficou claro que se tratava de estruturas com características muito diferentes. A divisão das duas atividades tinha duas metas: permitir um controle gerencial mais apurado para cada uma delas e concentrar o foco em cada uma das áreas de negócio. A carta deixava claro que a transformação de todas as unidades próprias em Famed Rede não seria realizada em uma única operação. Devido a procedimentos de ordem jurídica e burocrática, ela deveria ser paulatina e progressiva, a começar com a unidade que acabava de ser inaugurada.

Em outubro de 2004, foi apresentado um novo organograma para a empresa, explicitando a separação entre a operadora, a rede e a direção corporativa. A gestão da Famed Rede era exercida por um comitê formado pelos coordenadores das áreas de operações, apoio ao cliente, enfermagem, médica e saúde preventiva, sendo esse colegiado subordinado diretamente à diretoria. No fim daquele ano, foi apresentado o plano estratégico da Famed para 2005, que identificava, entre as ações com alta prioridade, o cumprimento das metas financeiras da Famed Rede e seu projeto de gestão, que incluía revisão de processos - com identificação de dificuldades e pontos fracos, e adequação de formulários; estudos de produtividade; problemas para o levantamento de informações e apresentação de soluções para todos os problemas identificados.

Entre agosto de 2004 e junho de 2005, muito pouca coisa mudou efetivamente nas unidades da rede própria, e diversas ações apontadas como imprescindíveis no documento distribuído aos médicos em julho de 2004 continuavam sem ocorrer, seja por parte das chefias, seja pelas demais instâncias da organização. Como exemplo, é possível citar a informatização dos prontuários - indicada como uma das metas de curto prazo - que se iniciou somente em maio de 2005 em apenas um dos centros médicos, ao passo que as outras unidades continuavam trabalhando com prontuários em papel. Ademais, nenhuma das ações relacionadas à Famed Rede no Plano Estratégico de 2005 estava concluída, assim como também não havia nenhuma mudança na política de cargos e salários.

Em julho de 2004, antes do início da coleta de dados da pesquisa, foi feita uma consulta ao diretor, explicando a intenção da pesquisa e solicitando autorização para sua realização. Na entrevista, o diretor manifestou sua concordância e relatou alguns fatos do processo de mudança, destacando, principalmente, a necessidade de que os gestores adquirissem uma visão de gestão de negócios totalmente inexistente até o momento. A seguir, apontou como um dos maiores problemas para a mudança o fato de os gestores estarem completamente envolvidos com as rotinas e problemas diários da operação: “Tem 
coisas que a gente pode melhorar, todos estão sendo tragados pelo dia a dia, não estamos conseguindo remar contra as águas". Manifestando frustração, falou do modelo de gestão de saúde da Famed e das críticas a seu respeito:

Eu defini um modelo que é a única coisa que me orienta. (...) Há quatro anos venho sendo criticado - é uma resistência velada por parte de diversos diretores e assessores. (...) Como eu não tenho outra pilastra em que me segurar, eu insisto nessa visão estratégica, (mas) os dados mostram que apesar de estarmos andando pra frente, estamos muito longe do objetivo.

Na convivência diária com os membros da organização, nas entrevistas informais e na observação das rotinas da empresa, vários aspectos do processo de mudança puderam ser levantados. Foram abordados diversos temas relativos à separação da Famed Rede, entre eles a ausência de integração das unidades, a dificuldade na definição das funções de diversas chefias e a falta de aderência ao modelo de atendimento.

No que se refere à busca da padronização das unidades, com unificação de procedimentos e forma de atendimento de todos os centros médicos, estava claro que as unidades continuavam funcionando de maneira totalmente independente. As informações fornecidas pelas diversas unidades eram diferentes e não havia comunicação entre os gerentes. Em uma conversa informal, um funcionário afirmou: "É como se a unidade X não fizesse parte da Famed". E concluiu: "Os processos acontecem de maneira diferente em cada unidade. Uma não tem conhecimento do funcionamento da outra".

Em relação ao modelo, foram dados diversos depoimentos confusos. A noção aparente é de que ele era pouco conhecido, bastante questionado e com apenas uma pequena parte posta em prática. Um gestor entrevistado criticou: "Ele acredita no ideal de saúde do pai. Já mostrei que esse modelo não dá retorno". Um médico afirmou: "Não sei o que é o modelo". Em reunião dos gestores com o diretor, este justificou o objetivo do modelo: "O modelo é racionalizar o atendimento em função das características da demanda. (...) Linha de ação: trabalhos que resultem num melhor uso. (...) Foco claro de organizar o trabalho". Mas finalizou revelando saber que as coisas não estavam funcionando da maneira desejada: "Os dados mostram que nosso modelo está fora de foco".

Um dos pontos mais relevantes destacados foi a definição da função dos gerentes médicos, ou a falta dela. Na verdade, a proposta indicada como uma das metas de curto prazo na carta de anúncio da inauguração da primeira unidade Famed Rede, de que a separação das empresas tornaria mais 
clara a definição das atividades de todos os profissionais, definitivamente não se concretizou. Uma das maiores dificuldades observadas no dia a dia tratava da confusão de papéis entre os gerentes médicos, gerentes operacionais e chefes de especialidades. Nos depoimentos de vários gerentes e funcionários era nítida a percepção de que todos têm dúvidas em relação às funções e responsabilidades de cada um dos profissionais, conforme desabafo feito por um funcionário: "Eu não sei nem pra quem eu devo encaminhar esse relatório". O diretor deixou claro que percebia a confusão existente: "Há ainda um descompasso muito grande entre as áreas, o que estamos fazendo aqui? Qual o caminho? Qual é o passo? (...) Erramos muito".

\section{As ações para contornar o impasse e a constatação do fracasso}

Em setembro de 2005, foi anunciado que o Comitê de Gestão da Famed Rede ficava temporariamente dissolvido porque sua composição "exigia mudanças para que seus integrantes pudessem se dedicar exclusivamente às tarefas de gestão". Pouco tempo depois, o diretor convocou uma reunião com os gestores da Famed Rede para alinhamento de estratégias. Na abertura do encontro, declarou ter conhecimento de que a situação estava confusa. Dirigindo-se aos gestores, afirmou saber que havia "desalinhamento e falta de entendimento entre papéis na tentativa de buscar um sistema melhor". Também apontou que o processo de mudança precisava de mais comunicação e não tinha seus passos definidos: "Não dá pra deixar claro na primeira fala. Não dá pra ver cada passo a priori". Porém, se mostrou descontente com a falta de compreensão por parte dos gestores: "Se a minha primeira linha de comando não consegue entender (...) Ainda tem coisas que eu falo e são interpretadas como ordem... aí 'caem na vala' porque podem ser besteiras. Não dá pra dizer o passo a passo". Ao finalizar a reunião apresentou um sentimento de preocupação: "Saio com a sensação de que estamos numa zona de perigo".

Em dezembro de 2005, foi apresentado um novo organograma consolidando alterações já efetuadas e oficializando a criação de um novo comitê para a gestão da Famed Rede. Após a comunicação, foi realizada mais uma reunião, com alguns gestores médicos e os membros do novo comitê, para falar dos objetivos da organização e da necessidade do acompanhamento de indicadores estratégicos e da tomada de atitudes para solução dos problemas existentes. Referindo-se ao novo comitê, alguns dos presen- 
tes manifestaram dúvidas em relação à eficácia desse modelo de gestão. O diretor explicou que o comitê não tinha função executiva: "O comitê não faz nada. Ele delibera e aprova como filtro para a diretoria". Afirmou também que o comitê deveria fiscalizar os custos: "(...) não podem tomar medidas que aumentem os gastos".

No final de 2005, foi contratada uma empresa de consultoria com a intenção de desenvolver um sistema de gestão por competências para toda a operação da Famed durante o ano de 2006. A primeira etapa do trabalho foi a realização de entrevistas individuais, feitas pela consultoria, ao longo do mês de dezembro de 2005. Foi selecionado um grupo de 35 pessoas entre os principais gestores da empresa. As entrevistas duraram cerca de uma hora e meia cada e foi assegurada a confidencialidade dos nomes. Apesar de não haver um questionário-padrão formal, os mesmos pontos foram abordados com todos os gestores.

As opiniões dos gestores nessas entrevistas foram reunidas e consolidadas em um relatório que foi apresentado ao diretor em janeiro de 2006. Logo após a leitura pelo diretor, o relatório foi apresentado e discutido, sob a forma de um workshop, com os consultores, o próprio diretor e 25 dos gestores entrevistados. O quadro 6 apresenta um resumo dos pontos abordados que interessam para este artigo. Nele, se encontram as opiniões listadas pelos consultores, acrescidas dos comentários realizados ao longo do workshop.

Na conclusão do workshop, o diretor destacou que o trabalho havia sido desenvolvido com base em entrevistas individuais com os gestores da empresa e que, destes, 25 estavam presentes. "Este é um retrato fiel, pintado pelos gestores da Famed, sobre a situação da empresa." A maioria dos gestores manifestou concordância com a afirmação dizendo que "se reconheciam no retrato". Ele complementou afirmando que, quando leu o relatório, a sensação foi semelhante àquela que temos algumas vezes ao olhar uma foto e pensar "Nossa... como eu estou gordo!" Todo o tempo se falou do "nosso negócio" sem nenhuma distinção entre rede e operadora.

No dia 30 de janeiro de 2006, último dia de coleta de dados da pesquisa, o diretor enviou aos gestores um e-mail que representava de maneira significativa o estado em que se encontrava o processo de mudança organizacional. Em um trecho da comunicação, ele revela a frustração com o estado da organização:

Hoje estive na unidade $\mathrm{X}$ com uma visita. (...) Creio que a última vez que estive na unidade foi há cerca de 3 ou 4 meses e algumas observações que fiz junto a 
Maria, hoje, continuavam imutáveis. Não é a primeira nem a segunda vez que pergunto ao responsável pelo centro médico o porquê de certas coisas e a resposta é ... 'já pedi”, "já falei”, "já passei”.

Estes fatos refletem problemas simples e imediatos e problemas muito mais complexos, que me preocupam mais: a falta de noção do quão urgente precisamos de gestores que assimilem a responsabilidade de ser um AGENTE gerador de resultados e soluções para agregar valor ao nosso negócio. Estamos no caminho, mas é preciso determinar o foco e, a partir deste, montar a equipe e produzir mudanças (...).

Parece claro que o processo de implementação da mudança não atendeu às expectativas da direção da empresa.

\section{Quadro 6 \\ Resumo da visão do diretor e principais gestores da organização no final da coleta de dados}

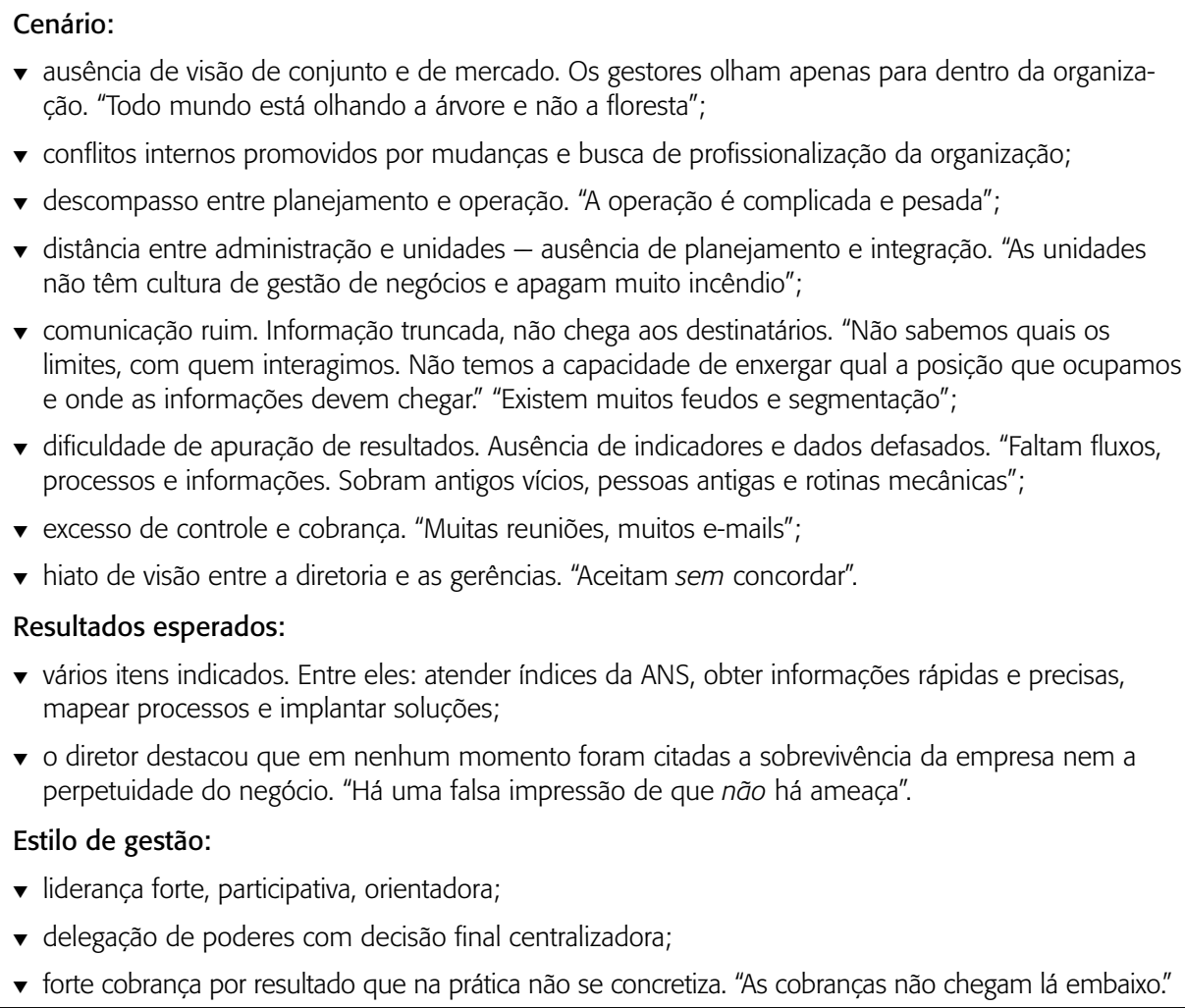

v ausência de visão de conjunto e de mercado. Os gestores olham apenas para dentro da organização. "Todo mundo está olhando a árvore e não a floresta";

v conflitos internos promovidos por mudanças e busca de profissionalização da organização;

v descompasso entre planejamento e operação. "A operação é complicada e pesada";

v distância entre administração e unidades - ausência de planejamento e integração. "As unidades não têm cultura de gestão de negócios e apagam muito incêndio";

v comunicação ruim. Informação truncada, não chega aos destinatários. "Não sabemos quais os limites, com quem interagimos. Não temos a capacidade de enxergar qual a posição que ocupamos e onde as informações devem chegar." "Existem muitos feudos e segmentação";

v dificuldade de apuração de resultados. Ausência de indicadores e dados defasados. "Faltam fluxos, processos e informações. Sobram antigos vícios, pessoas antigas e rotinas mecânicas";

v excesso de controle e cobrança. "Muitas reuniões, muitos e-mails";

v hiato de visão entre a diretoria e as gerências. "Aceitam sem concordar".

Resultados esperados:

v vários itens indicados. Entre eles: atender índices da ANS, obter informações rápidas e precisas, mapear processos e implantar soluções;

v o diretor destacou que em nenhum momento foram citadas a sobrevivência da empresa nem a perpetuidade do negócio. "Há uma falsa impressão de que não há ameaça".

Estilo de gestão:

- liderança forte, participativa, orientadora;

v delegação de poderes com decisão final centralizadora;

v forte cobrança por resultado que na prática não se concretiza. "As cobranças não chegam lá embaixo."

Continua 


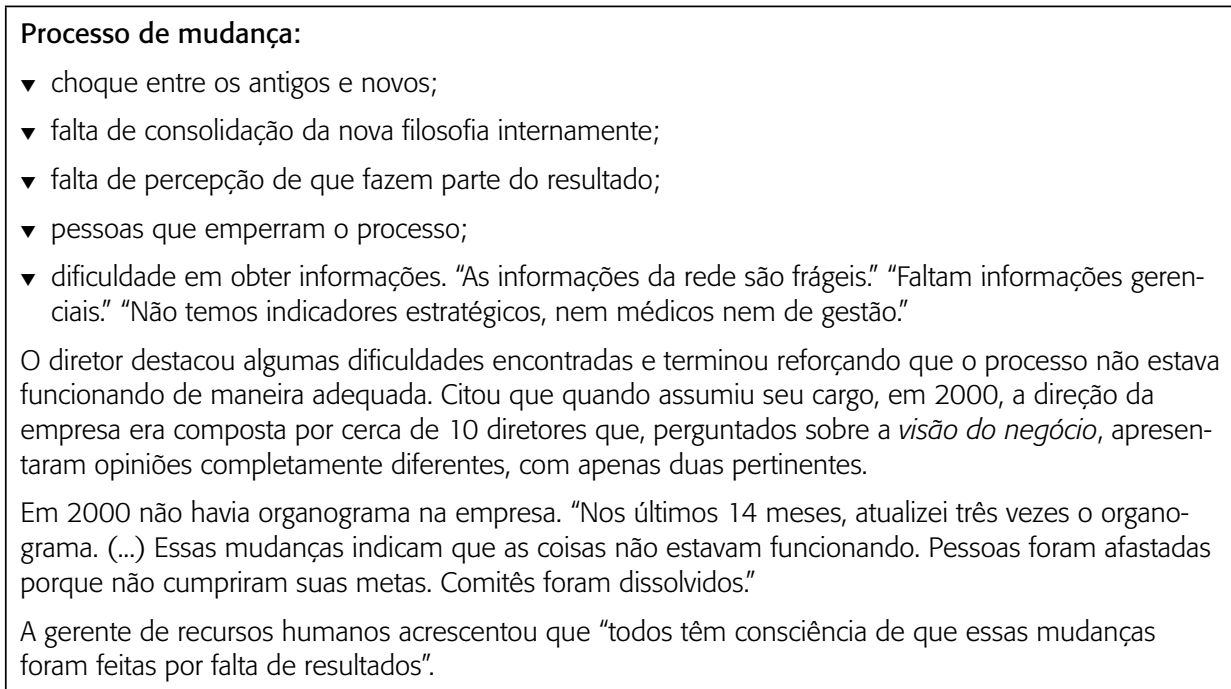

\section{Análise da mudança organizacional}

A partir da descrição do processo de mudança com base nos resultados da pesquisa de campo, é apresentada a análise da mudança organizacional, contrapondo-a com as etapas do modelo proposto por John P. Kotter.

\section{Conceito e classificações diante do modelo de Kotter}

A criação da Famed Rede representa isoladamente uma mudança organizacional completa. De acordo com as classificações apresentadas pelos diversos autores na segunda seção deste artigo, a separação da Famed Rede representa um tipo de mudança transformacional, de segunda ordem, descontínua e radical. É um processo de mudança episódico e intencional e para a garantia de sua implementação é necessário que ela seja dirigida.

É interessante destacar a diferença entre a intenção da mudança na visão do diretor e a percepção da organização sobre o processo. A mudança almejada é uma macromudança, na definição de Mintzberg, Ahlstrand e Lampel (1998), mas os gestores estão focados em uma micromudança, pois olham apenas para dentro da organização. Na visão dos gestores, o processo de mudança é o oposto do desejado pelo diretor, pois eles o tratam como um processo linear e contínuo, com pequenas alterações e ajustes nos padrões 
existentes. Outro ponto interessante a destacar no processo é a diferença entre as duas maneiras básicas de lidar com a mudança organizacional: de forma reativa e de forma proativa. A intenção do diretor é mudar deliberadamente o status quo da organização, mas a realidade mostra que na rotina dos gestores os problemas vinham sendo resolvidos à medida que apareciam.

Em relação às propostas de Kotter, seis dos oito erros mais comuns apontados pelo autor são facilmente identificados no caso estudado. Eles são apresentados no quadro 7.

\section{Erros identificados no processo de mudança estudado}

\begin{tabular}{|ll|}
\hline $\begin{array}{l}\text { Permitir complacência. } \\
\text { Falhar na criação de uma } \\
\text { coalizão administrativa forte. }\end{array}$ & $\begin{array}{l}\text { Entre os gestores da Famed não há senso de urgência. } \\
\text { completar um ano. Não foi identificado um grupo de pessoas } \\
\text { comprometidas com a mudança e com poder suficiente para liderar o } \\
\text { processo. }\end{array}$ \\
$\begin{array}{ll}\text { Subestimar o poder da visão } \\
\text { corporativa. }\end{array}$ & $\begin{array}{l}\text { Não há uma visão clara e apropriada sobre o processo de } \\
\text { transformação. Os esforços de mudança são desalinhados. }\end{array}$ \\
$\begin{array}{ll}\text { Comunicar a visão de forma } \\
\text { ineficiente. }\end{array}$ & $\begin{array}{l}\text { A comunicação é abundante, porém ineficiente. Há excesso de mensa- } \\
\text { gens e reuniões, mas pouca clareza na definição de responsabilidades }\end{array}$ \\
$\begin{array}{l}\text { Permitir que obstáculos blo- } \\
\text { queiem a nova visão. }\end{array}$ & $\begin{array}{l}\text { Os gestores tendem a ficar paralisados quando encontram alguma } \\
\text { entrificuldade. }\end{array}$ \\
$\begin{array}{l}\text { Falhar na criação de vitórias } \\
\text { de curto prazo. }\end{array}$ & $\begin{array}{l}\text { Não há sinais visíveis de que estão sendo produzidos resultados espe- } \\
\text { rados. Há mensagens claras indicando falhas. }\end{array}$ \\
\hline
\end{tabular}

A seguir é apresentada uma avaliação de como o processo de mudança se comportou em relação a cada um dos passos indicados pelo autor.

\section{Primeiro passo: estabelecer um senso de urgência}

$\mathrm{Na}$ avaliação do processo de mudança da Famed Rede é fácil perceber que não há um senso de urgência estabelecido. O comentário do diretor na última comunicação registrada reforça essa afirmação: “(...) problemas muito mais complexos e que me preocupam mais: a falta de noção do quão urgente precisamos de gestores que assimilem a responsabilidade de ser um agente gerador de resultados e soluções para agregar valor ao nosso negócio”. 


\section{Segundo passo: criar uma coalizão para a liderança}

Na criação da estrutura independente para a Famed Rede, foi instituído um comitê para sua gestão. Essa iniciativa parecia estar de acordo com as indicações do autor. O comitê foi formado por um membro de cada uma das áreas da empresa, com posição gerencial. A instituição do comitê de gestão parecia um bom passo, porém sua dissolução, menos de um ano depois de ter sido criado, aponta que a equipe não funcionou de maneira adequada. Alguns comentários do diretor parecem esclarecer os motivos. Explicando aos gestores a função do comitê, ele afirmou: "O comitê não faz nada", deixando claro, desse modo, a baixa autonomia para promover as mudanças. Afirmou também que os membros do comitê “(...) não podem tomar medidas que aumentem os gastos”. Ou seja, além de não possuírem poder, também não possuíam orçamento.

\section{Terceiro passo: desenvolver visão e estratégia}

O processo de mudança estudado não apresenta uma visão clara. Em diversos pontos das entrevistas, documentos e reuniões, surgiram comentários sobre a ausência de metas e desconhecimento do planejamento estratégico, apesar da existência do documento Plano Estratégico 2005, apresentado no final de 2004. O relatório da consultoria de gestão por competência destacou a existência de um hiato entre a diretoria e as gerências. É importante ressaltar que esses comentários foram feitos na presença do diretor. É interessante notar que a separação da organização em operadora e rede é anunciada e indicada como necessária e vantajosa, porém, a missão apresentada é apenas uma para as duas empresas.

\section{Quarto passo: comunicar a visão da mudança}

Para Kotter (1998), é necessário que os três primeiros passos tenham ocorrido sem falhas para que a comunicação da visão possa ser efetiva. Ou seja, na ausência de um elevado senso de urgência as pessoas podem não demonstrar interesse em conhecer a nova visão; se a seleção do grupo da coalizão administrativa não tiver sido adequada, ocasionará dificuldade na criação e no envio da mensagem apropriada, e se a visão não tiver sido bem-elaborada nenhuma comunicação poderá ser eficaz. Além de todos esses pontos serem percebidos no processo de mudança em questão, vários problemas de comunicação são 
indicados nas entrevistas e documentos analisados. A partir de documentos internos e de entrevistas, as opiniões sobre a comunicação são unânimes em identificá-la como um ponto negativo.

\section{Quinto passo: dar empowerment aos funcionários para realização de ações abrangentes}

Como indicado nas entrevistas e nos documentos analisados, o diretor exerce uma liderança forte com decisão final centralizadora. A delegação de poderes indicada no tópico que se refere ao estilo de gestão no relatório é restrita e limitada, e tem regras pouco claras, dando a impressão de seguir critérios pessoais. Como destaca Kotter (1998), a ausência do empowerment faz com que os funcionários não se sintam capazes de enfrentar as mudanças e desistam de ajudar e tomar as providências necessárias.

\section{Sexto passo: gerar vitórias de curto prazo}

Para Kotter (1998), uma boa vitória de curto prazo deve possuir pelo menos uma dessas três características: visibilidade, permitindo que um grande número de pessoas consiga enxergar por conta própria se os resultados são efetivos ou não; ausência de ambiguidade, com pouca argumentação a respeito do resultado obtido; e relação clara com o esforço de mudança. No caso estudado não foi possível encontrar evidência de comemorações de vitórias de curto prazo. Não há sinais visíveis de que estão sendo produzidos resultados esperados. Há, porém, mensagens claras indicando falhas.

\section{Sétimo passo: consolidar os ganhos e produzir mais mudanças}

Segundo Kotter, nas transformações bem-sucedidas, a coalizão administrativa utiliza a credibilidade proporcionada pelas conquistas de curto prazo para impulsionar o processo, empreendendo ainda mais projetos ou projetos maiores. No caso da criação da Famed Rede, não foi identificada uma coalizão administrativa forte, nem a celebração de conquistas de curto prazo. Portanto, torna-se impossível o passo de consolidação dos ganhos seguido da produção de mais mudanças. 


\section{Oitavo passo: incorporar as mudanças à cultura da organização}

A transformação cultural é o último passo indicado por Kotter (1998) para a implementação de um processo de mudança, porque demanda muito tempo para que seja efetiva. Os valores compartilhados são produto de muitos anos de experiência da organização e, portanto, diversos anos da nova experiência são necessários para que qualquer alteração seja consolidada. No caso da Famed Rede, é fácil perceber que as mudanças ainda não ocorreram da maneira desejada, e muito pouca coisa — ou quase nada - se alterou na cultura da organização. Apesar de os passos não terem ocorrido de maneira correta, não permitindo, portanto, que ocorra a incorporação das mudanças à cultura da organização, o autor indica que essa preocupação deve estar presente desde as primeiras fases do projeto de mudança, pois sua compreensão é fundamental na elaboração de cada uma das etapas. As mudanças não incorporadas à cultura da organização costumam ser muito frágeis e estão sujeitas à regressão.

Concluindo a análise da mudança da Famed Rede de acordo com os oito passos indicados por Kotter, percebe-se que praticamente nenhum deles foi seguido. A ausência desses passos parece realmente indicar a existência de falhas presentes no processo e explicar algumas das dificuldades encontradas.

\section{Conclusão e considerações finais}

No cenário atual, as organizações no mundo todo vêm enfrentando um clima constante de mudança nos negócios. Muitas estão se reestruturando devido aos novos desafios, e as incapazes de se adaptar enfrentam sérios problemas de sobrevivência. A despeito da relevância do tema, diversas pesquisas revelam que a maioria das iniciativas de mudança fracassa. $\mathrm{O}$ envolvimento de pessoas talentosas e comprometidas conduzindo a mudança, com substanciais recursos alocados a esse esforço e altos interesses em risco, não garante a eficácia dessas mudanças. Daí a importância da busca de ferramentas que auxiliem o gestor nesse inevitável e arriscado processo. Assim, este artigo analisou o resultado de um processo de mudança em empresa de médio porte do setor médico, contrapondo sua condução ao modelo de John Kotter.

A avaliação do processo de mudança da empresa levou à constatação de que ele não foi bem-sucedido no período estudado, com base nas percepções dos gestores e da alta administração da empresa. Em relação ao modelo proposto, percebeu-se que a empresa não seguiu seus passos, o que pode explicar algumas das dificuldades encontradas. 
Todavia, um modelo, que é uma redução da realidade, não consegue captar a totalidade dos fatores intervenientes em processos de transformação. Cabe ressaltar as características de empresa familiar, a despeito de seu tamanho e complexidade, que podem mascarar relações de poder não descortinadas pelas orientações de Kotter. Não raro, um processo sucessório traz, em seu bojo, históricos familiares que podem sensibilizar emoções e afetar a racionalidade de tomadas de decisão, agredindo a eficácia organizacional em um momento tão crítico. É plausível supor que situações semelhantes surjam de forma importante em outras empresas familiares brasileiras do mesmo porte.

Pensar em mudança sem que a liderança seja pesadamente considerada é outro dado que suscita consideração, e não fica claro até que ponto as características pessoais do principal gestor influenciaram, conscientemente ou não, suas opções estratégicas no decorrer do processo. Ao longo deste artigo podese perceber a forte influência da personalidade do diretor, com sua gestão centralizadora, no processo. A ser verdade tal conjectura, haveria uma explicação para o fato de apenas alguns passos do modelo terem sido seguidos, a despeito de uma verbalização que aponta para a uma nova ordem.

Por último, deve ser mencionada também a forte resistência dos membros da organização em relação à mudança, perceptível no decorrer das entrevistas. Esses aspectos, porém, não fizeram parte do foco deste artigo, ficando a sugestão de que novas pesquisas sejam feitas nessas áreas, em especial apontando para as relações entre a personalidade do gestor responsável na condução da mudança e a empresa, e seus laços familiares com o patriarca, para o caso de organizações em fase de sucessão.

\section{Referências}

ABRAMGE. Informe de imprensa - setembro de 2005. Disponível em: <www. abramge.com.br/internas.asp? secaonome $=$ informe $>$. Acesso em: jan. 2006.

BARDIN, Laurance. Análise de conteúdo. Lisboa: Edições 70, 1977.

BECKER, B. E. et al. Gestão estratégica de pessoas com o "scorecard". Rio de Janeiro: Campus, 2001.

BRESSAN, Cyndia Laura. Uma contribuição à compreensão do fenômeno da mudança organizacional a partir da percepção gerencial. 2001. Dissertação (Mestrado) — Instituto de Psicologia/UnB, Brasília, 2001. 
FORD, Jeffrey D.; FORD, Laurie W. The role of conversations in producing change in organizations. Academy of Management Review, v. 20, n. 3, p. 541-570, 1995.

FRANCISCO, Roberto da Piedade. Metodologia de gestão de mudanças para apoiar a implementação e manutenção de um sistema de gestão de qualidade. 2003. Dissertação (Mestrado em Administração) - Departamento de Administração, UFSC, Florianópolis.

HAMMER, M. A agenda: o que as empresas devem fazer para dominar esta década. Rio de Janeiro: Campus, 2002.

HUBER, G. P.; GLICK, W. H. Sources and forms of organizational change. In: (Eds.). Organizational change and redesign. New York: Oxford University Press, 1995.

KOTTER, J. P. Leading change. Boston: Harvard Business School Press, 1996.

. Winning at change. Leader to Leader Journal, n. 10, Fall 1998.

; COHEN, D. S. O coração da mudança. Rio de Janeiro: Campus, 2002.

LEWIN, K. Field theory in social science. Nova York: Harper \& Row, 1951.

LIMA, S. M. V.; BRESSAN, C. L. Mudança organizacional: uma introdução. In: 2003. (Org.). Mudança organizacional: teoria e gestão. Rio de Janeiro: FGV,

MINTZBERG, H.; AHLSTRAND, B.; LAMPEL, J. Strategy safari: a guided tour through the wilds of strategic management. New York: The Free Press, 1998.

NADLER, D. A.; SHAW, R. B.; WALTON, A. E. Discontinuous change: leading organizational transformation. São Francisco: The Jossey-Bass, 1994. (Management Series, 2).

NEIVA, Elaine Rabelo. Metodologia para avaliação da mudança organizacional. In: LIMA, Suzana Maria Valle et al. Mudança organizacional: teoria e gestão. Rio de Janeiro: FGV, 2003.

PORRAS, J. J.; ROBERTSON, J. Organizational development: theory, practice and research. In: DUNNETTE, M. D.; HOUGH, L. M. (Eds.). Handbook of industrial and organizational psychology. Palo Alto, California: Consulting Psychologists Press, 1992.

; ___ _ ROBERTS, D. R. Dynamics of planned organizational change: assessing empirical support for a theoretical model. Academy of Management Journal, June 1993. 
RONDEAU, Alain. Transformer l'organisation comprendre les forces que façonnent l'organisation et le travail. Gestion, v. 24, n. 3, 1999.

SILVA, J. R. Gomes da. Comunicação e mudança em organizações brasileiras: desvendando um quadro de referência sob a ótica do sujeito e da reconstrução de identidades. 2001. Tese (Doutorado em Administração) — Instituto de Administração e Gerência, PUC-Rio, Rio de Janeiro.

SILVA, José S. El cambio de época, el modo emergente de producción de conocimiento y los papeles cambiantes de la investigación y extension en la academia del siglo XXI. In: CONFERENCIA INTERAMERICANA DE EDUCACIÓN AGRÍCOLA SUPERIOR Y RURAL. 1999. Anales... Panamá: Instituto Interamericano de Cooperação para a Agricultura (IICA), 1999.

SOUZA SILVA, José de. A mudança de época e o contexto global cambiante: implicações para a mudança institucional em organizações de desenvolvimento. In: LIMA, Suzana Maria Valle et al. Mudança organizacional: teoria e gestão. Rio de Janeiro: FGV, 2003.

TRIVIÑOS, A. N. S. Introdução à pesquisa em ciências sociais: a pesquisa qualitativa em educação. São Paulo: Atlas, 1990.

VERGARA, Sylvia Constant. Projetos e relatórios de pesquisa em administração. São Paulo: Atlas, 2004.

WEICK, K. E.; QUINN, R. E. Organizational change and development. Annual Review of Psychology, n. 50, p. 361-387, 1999.

WOOD JR., Thomaz. (Org.). Mudança organizacional. São Paulo: Atlas, 2000. 